\title{
Amphiphilic Poly (3-Hydroxy Alkanoate)s: Potential Candidates for Medical Applications
}

\author{
Baki HAZER \\ Department of Chemistry, Zonguldak Karaelmas University, Zonguldak, Turkey \\ Email: bkhazer@karaelmas.edu.tr
}

\begin{abstract}
Poly (3-hydroxy alkanoate)s, PHAs, have been very attractive as biomaterials due to their biodegradability and biocompatibility. These hydrophobic natural polyesters, PHAs, need to have hydrophilic character particularly for drug delivery systems. In this manner, poly (ethylene glycol) (PEG) and hydrophilic functional groups such as amine, hydroxyl, carboxyl and sulfonic acid have been introduced into the PHAs in order to obtain amphiphilic polymers. This review involves in the synthesis and characterization of the amphiphilic PHAs.
\end{abstract}

Keywords: poly (3-hydroxy alkanoate), PHA, amphiphilic polymer, biomaterial, chemical modification

\section{Introduction}

Biomaterials have been widely used in medical applications, such as drug delivery, tissue engineering, devicebased therapies and medical imaging [1,2]. Synthetic and naturally occurring polymers have played important role in the treatment of disease and the improvement of health care. Among them, PHAs are promising materials for biomedical applications in tissue engineering and drug delivery system because they are natural, renewable, biodegradable and biocompatible thermoplastics. PHAs have been used to develop devices, including sutures, nerve repair devices, repair patches, slings, cardiovascular patches, orthopedic pins, adhesion barriers stents, guided tissue repair/regeneration devices, articular cartilage repair devices, nerve guides, tendon repair devices, bone-marrow scaffolds, tissue engineered cardiovascular devices and wound dressing. However the direct use these polyesters has been hampered by their hydrophobic character and some physical shortcomings [3]. The key to biocompatibility of biomedical implanttable materials is to render their surface in a way that minimizes hydrophobic interaction with the surrounding tissue. Therefore, hydrophilic groups have been introduced into the PHAs in order to obtain amphiphilic polymer. This review has been focused on the chemically modified PHAs enhanced hydrophilic character as biomaterials for medical applications.

\section{PHAs}

PHAs are accumulated as intracellular granules as a result of a metabolic stress upon imbalanced growth due to a limited supply of an essential nutrient and the presence of an excess of a carbon source. These novel biopolymers have material properties ranging from rigid and highly crystalline to flexible, rather amorphous and elastomeric. There have been many studies reported on the modification reactions to enhance mechanical and thermal properties to prepare new biomaterials for the medical applications [4-13]. PHAs can be classified into three groups based on the number of carbon atoms in the monomer units: short-chain-length (sclPHA) containing 3-5 carbon atoms that are produced by Ralstonia eutropha (also referred Watersia eutropha, A. Eutrophus), medium-chain-length (mclPHA) containing 6-14 carbon atoms, and long-chain-length (lclPHAs), with more than 14 carbon atoms $[14,15]$. Pseudomonas oleovorans is a very versatile for PHA production because it can produce medium chain length polyesters (mclPHA) and long chain length polyesters (IclPHA) from a wide variety of carbon substrates. These types of the bacterial polyesters have been summarized in Table 1 .

\section{Amphiphilic PHAs}

Amphiphilic polymers can be synthesized by introducing hydrophilic groups such as hydroxyl, carboxyl, amine, glycol and hydrophilic polymers such as PEG, poly (vinyl alcohol), polyacryl amide, poly acrylic acids, hydroxy ethyl methacrylate, poly vinyl pyridine and poly vinyl pyrrolidone to a hydrophobic moiety. Because of their ability to form micelles, amphiphilic block copolymers are strong candidates for potential applications as emulsifiers, dispersants, foamers, thickeners, rinse aids, and compatibilizers [16,17]. Similarly, amphiphilic PHAs can also be synthesized by introducing hydrophilic groups such as hydroxyl, carboxyl, amine, 
Table 1. Classification of the bacterial polyesters

\begin{tabular}{|c|c|c|c|c|c|c|}
\hline & & $\underset{\mathrm{T}}{\mathrm{TO}-\mathrm{C}}$ & $\begin{array}{l}\mathrm{O}^{\mathrm{II}} \mathrm{C} \\
\text { A) }\end{array}$ & & & \\
\hline \multirow{2}{*}{ Carbon Source } & \multicolumn{3}{|c|}{ Poly (3-hydroxy alkanoate) (PHA) } & \multicolumn{3}{|c|}{ Thermal and Mechanical Properties } \\
\hline & Type & Side chain (R) & Name* & $\mathrm{T}_{\mathrm{g}}\left({ }^{\circ} \mathrm{C}\right)$ & $\mathrm{T}_{\mathrm{m}}\left({ }^{\circ} \mathrm{C}\right)$ & Elongation (\%) \\
\hline $\begin{array}{l}\text { Sugar, glucose, acetic } \\
\text { acid }\end{array}$ & $\begin{array}{l}\text { Short chain } \\
\text { length }\end{array}$ & Methyl, ethyl & $\begin{array}{l}\text { PHB } \\
\text { PHV }\end{array}$ & 15 & 170 & 5 \\
\hline $\begin{array}{l}\text { Alkanoic acids, alkanes } \\
\text { and alkanols }\end{array}$ & $\begin{array}{l}\text { Medium chain } \\
\text { length }\end{array}$ & $\begin{array}{l}\text { Propyl, butyl, pentyl, } \\
\text { hexyl, heptyl }\end{array}$ & $\begin{array}{l}\text { PHHx } \\
\text { PHHp } \\
\text { PHO } \\
\text { PHN } \\
\text { PHD }\end{array}$ & -40 & 60 & 800 \\
\hline Plant oily acids & $\begin{array}{l}\text { Long chain } \\
\text { length }\end{array}$ & $\begin{array}{l}\text { More than } 14 \text { Carbon per } \\
\text { repeating unit }\end{array}$ & & -50 & 40 & Soft, sticky \\
\hline
\end{tabular}

*B: butyrate, V: valerate, Hx: hexanoate, Hp: heptenoate, $\mathrm{O}$ : octanoate, $\mathrm{N}$ : nonanoate, $\mathrm{D}$ : decanoate. $\mathrm{T}_{\mathrm{g}}$ and $\mathrm{T}_{\mathrm{m}}$ are glass and melting temperatures, respectively.

sulfonic acid, ethylene glycol and PEG. PEG is a polyether that is known for its exceptional blood and tissue compatibility. It is used extensively as biomaterial in a variety of drug delivery vehicles and is also under investtigation as surface coating for biomedical implants. PEG, when dissolved in water, has a low interfacial free energy and exhibits rapid chain motion, and its large excluded volume leads to steric repulsion of approaching molecules [18]. These properties make PEG excellent biocompatible material. Hydroxylation of the PHAs can be carried out by using both biosynthetically and chemical modification. The biosynthetic hydroxylation of the PHAs has successfully been reviewed by Foster, recently [19].

Chemical modifications of the PHAs have been extensively studied $[6,9,15,20,21]$. In this review, selective chemical modification reactions in order to obtain amphiphilic PHAs and some potential applications in biotechnology will be discussed.

\section{Synthesis of Amphiphilic PHAs}

Selective chemical modification of the PHAs involves functionalization and grafting reactions of the PHAs. Hydrophilic groups such as hydroxyl, carboxyl, amine, glycol and sulfonic acid can be introduced into the PHAs by means of functionalization. In grafting reactions, some hydrophilic groups have been attached in the PHA chain to obtain amphiphilic polymer.

\subsection{Trans Esterification}

Some ester group(s) of the PHA is exchanged with an alcohol in transesterification process. Transesterification is carried out in melt or in solution. Hydroxylation of the PHBs via chemical modification is usually achieved by the transesterification reactions to obtain diol ended PHB. Transesterification reactions in the melt between poly (ethylene glycol), mPEG, and PHB yield diblock amphiphilic copolymer with a dramatic decrease in molecular weight [22]. Catalyzed transesterification in the melt is used to produce diblock copolymers of poly ([R]-3-hydroxybutyric acid), PHB, and monomethoxy poly (ethylene glycol), mPEG, in the presence of a catalyst, in a one-step process. The formation of diblocks is accomplished by the nucleophilic attack from the hydroxyl end-group of the mPEG catalyzed by bis (2-ethylhexanoate) tin.

When the transesterification reaction between PHB and ethylene glycol in diglyme as a solvent is carried out, the telechelic PHB with MW at around 2000 Dalton is obtained [23]. Stannous octanoate as a transesterification catalyst causes the reaction of carboxylic end group and diol, quantitatively. Basically, short chain diol or polyol moiety can rarely renders a hydrophilic character to the longer hydrophobic PHA. Therefore amphiphilic character of the telechelic PHAs and PEGylated PHAs have been stood poor.

Telecehelic PHB obtained by this way can be used in the preparation of the polyester urethanes via diisocyanate chain extension reaction with synthetic aliphatic polyester as soft segment [24]. PHB-g-PCL graft copolyester urethane samples exhibited the elongation at break up to $900 \%$.

Two segmented biodegradable poly (ester-urethane) series, based on bacterial PHB as the hard segments, and either PCL or PBA as the soft segments, were easily 
(a)

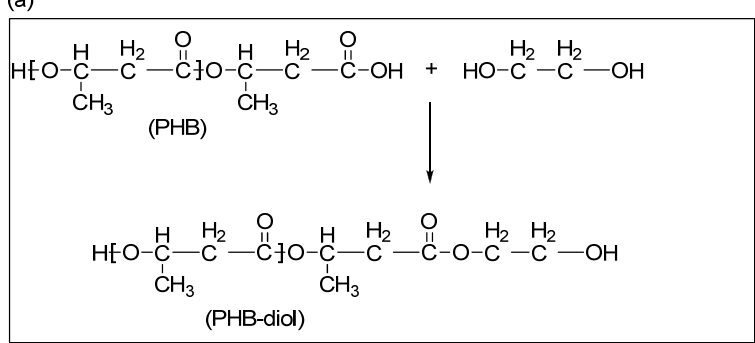

(b)

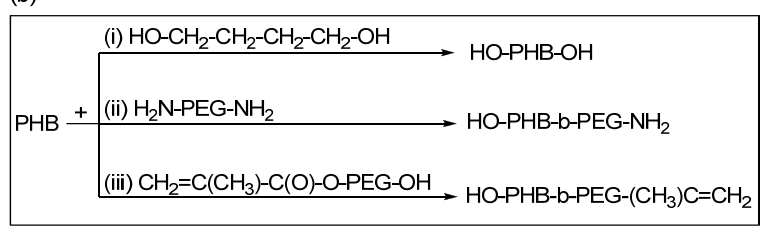

Figure 1. (a) Formation of the diol ended PHB via transesterification in the presence of ethylene glycol. (b) Transesterification reactions of $\mathrm{PHB}$ with (i) butane diol, (ii) transamidation with bisaminopropyl ended PEG, and (iii) transesterification reactions of PHB with methacryloyl oxy ethylene glycol in solution

synthesized by one-step solution polymerizations. Transesterification reaction of PHB with methacryloyl oxy poly (ethylene glycol) (MW: 526), poly (ethylene glycol) bis (2-aminopropyl ether) with MW 1000 and 2000 was achieved to obtain PHB-b-PEG telechelic diblock copolymers [25]. Similarly, telechelic PHB can also be obtained by transesterification with 1,4-butane diol in 1,2-dichloro benzene under reflux conditions. The transesterification reactions can be designed in Figure 1.

\subsection{Oxidation of the Pendant Double Bonds}

Most used unsaturated PHAs are mclPHAs obtained from unsaturated edible oils and synthetic olefinic substrates. When Pseudomonas oleovorans is grown on unsaturated carbon source such as soybean oily acids, 7-octenoic acid and 10-undecenoic acid, unsaturated PHAs are obtained [26]. Figure 2 shows the synthesis of the unsaturated PHAs.

Microbial polyesters containing unsaturated side chains are open the way for chemical modification reactions to prepare PHA derivatives. Pendent double bonds of the poly (3-hydroxy octanoate-co-10-undecenoate), $\mathrm{PH}(\mathrm{O}) \mathrm{U}$, can be oxidized to the diol (PHOU-diol) and carboxylic acid (PHOU-COOH). $\mathrm{KMnO}_{4}$ is used as an oxidizing agent. In mild conditions PHOU-diol is obtained [27]. While PHOU was insoluble in a polar solvent, PHOU-diol was soluble in methanol, acetone/ water $(80 / 20, \mathrm{v} / \mathrm{v})$ and DMSO, even with $40-60 \%$ of double bonds unconverted, but it was insoluble in non-polar solvents such as chloroform, THF, acetone. Figure 3 shows the PHOU-diol.
Poly(3-hydroxy-octanoate-co-10-undecenoate) (PHOU)

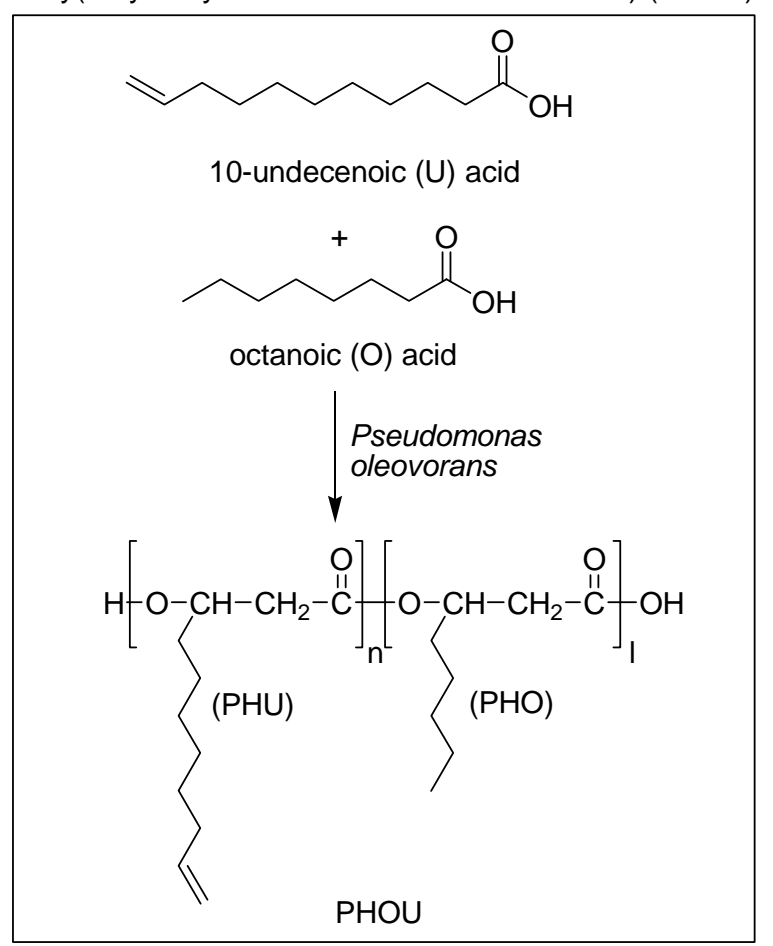

Poly(3-hydroxy alkenoate) from soybean oil (PHA-Sy)

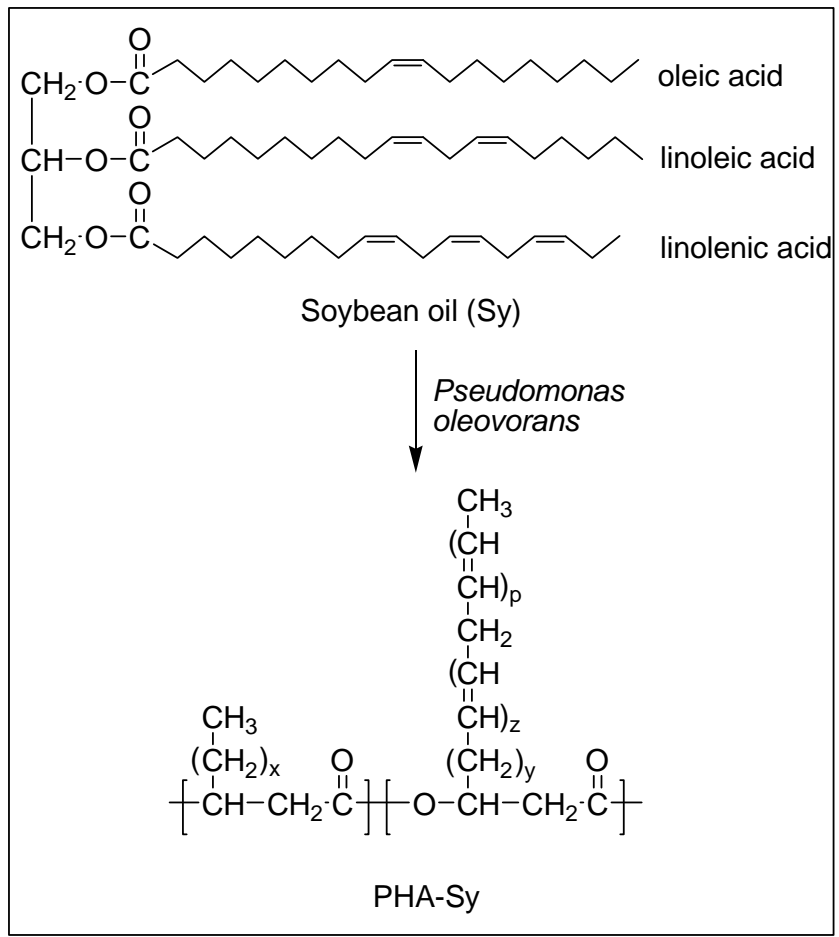

Figure 2. Synthesis of two types of unsaturated PHAs from Pseudomonas oleovorans (i) grown on soybean (PHA-Sy) and (ii) 10-undecenoic acid and octanoic acid (PHOU) 
<smiles>C=C(C)CC(CC(=O)OC(C)(C)C(=O)OC(CC(=O)O)CC(CC)OC(C)(C)C)OC(C)(C)C</smiles>

Figure 3. PHOU with pendant hydroxyl groups

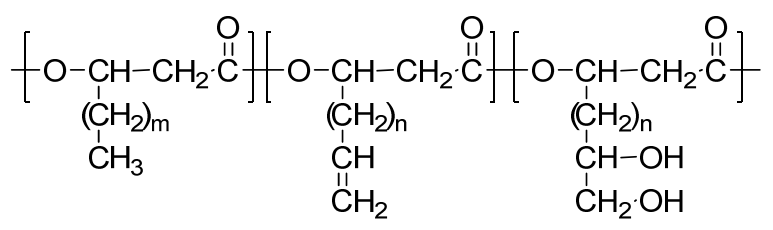

Figure 4. PHOU with pendant carboxylic acids (PHOU-COOH)

The use of $\mathrm{NaHCO}_{3}$ even in hot solution $\left(55^{\circ} \mathrm{C}\right)$ resulted mainly in diol groups, not carboxylic groups, while the same reaction at room temperature using $\mathrm{KHCO}_{3}$, led to the conversion of the pendant unsaturated groups to the carboxyl groups [28]. Figure 4 shows the PHOU with pendant carboxyl groups.

Carboxylation of $\mathrm{PHOU}$ using $\mathrm{OsO}_{4}$ as oxidant can be performed with the small decrease in MW after the reaction [29]. The quantitative hydroxylation of pendant vinyl groups of PHU with the use of either the borobicyclononane or the borane-tetrahydrofuran complex is also achieved in high yield [30]. After hydroxylation, the thermal stability and the molecular weight of the hydroxylated PHU showed small decreases; however, full solubility in methanol and almost full solubility in water are achieved [30].

Water wettability of saturated PHAs, poly(3-hydroxy butyrate) (PHB) and poly(3-hydroxy butyrate-co-3hydroxy hexanoate) (PHBHHx) can also be improved by carboxyl ion implantation. Ion implantation is performed at an energy of $150 \mathrm{keV}$ with fluences ranging from $5 \times 10^{12}$ to $1 \times 10^{15}$ ions $/ \mathrm{cm}^{2}$. Contact angle measurements are confirmed that the ion implantation improves the water wettability [31].

Epoxidation of the unsaturated polyester with m-chloroperbenzoic acid, as a chemical reagent, yields to quantitative conversions of the unsaturated groups into epoxy groups [32]. Primary and secondary amines can be reacted with epoxide groups to yield hydrophilic compounds.

Reaction between hexamethylene diamine with epoxidized PHOU provides crosslinked polyester [33].

Enhenced hydrophilicity of the PHOU has recently been achieved by the reaction between epoxidized PHOU and diethanol amine to give highly hydrophilic polyester, PHON [34]. The first reaction involved the transformation of the vinyl-terminated side chains of PHOU to epoxide groups (PHOE). Figure 5 shows to the conversion reaction of epoxidized PHOU (PHOE) to hydroxylated PHOU in the presence of diethanol amine (PHON).

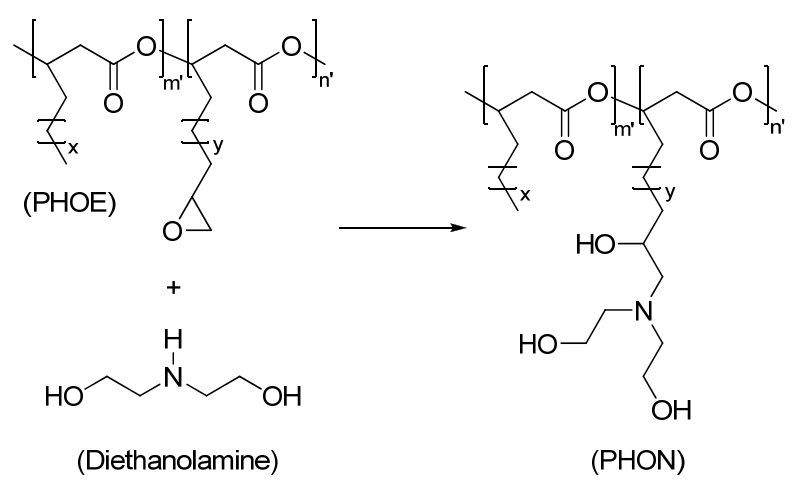

Figure 5. The conversion reaction of epoxidized-PHOU (PHOE) to hydroxylated PHOU in the presence of diethanol amine (PHON)

The successful side chain conversion was further substantiated by the change in solubility when converting PHOU to PHOE to PHON. As the functionalized side chains became more polar, the polymer became soluble in more polar solvents. In this respect, PHON was soluble in water.

\subsection{Quarternization and Sulfonation of the PHAs}

Halogenation of the polymers is a versatile method to open the way for further functionalization $[25,35,36]$. Addition of the chlorine and bromine into the double bond is quantitative and halogenated PHAs can be easily obtained by this way [25]. Chlorination is performed by either the addition to double bonds of the unsaturated PHA obtained from soybean oil (PHA-Sy) or substitution reactions with saturated hydrocarbon groups $[35,36]$. Chlorination of the sticky, soft PHA-Sy with double bond provides polyester with hard, brittle, and crystalline physical properties depending on the chlorine content. By this way, it is possible to introduce $35 \mathrm{wt} \%$ chlorine to the PHA. In case of the chlorinated PHO, glass transition temperature has been shifted to $+2^{\circ} \mathrm{C}$ from -40 ${ }^{\circ} \mathrm{C}$ [36]. For further functionalization, quaternization reactions of the chlorinated PHA with triethylamine (or triethanol amine) can be performed. Additionally, aqueous solution of $\mathrm{Na}_{2} \mathrm{~S}_{2} \mathrm{O}_{3} \cdot 5 \mathrm{H}_{2} \mathrm{O}$ can be reacted with solution of $\mathrm{PHA}-\mathrm{Cl}$ in acetone to give sulfonate derivative of the $\mathrm{PHO}$ [36].

\subsection{Grafting Reactions of the PHAs}

\subsubsection{Chitosan Grafting}

Chemical modifications of chitosan by grafting method are important to prepare multifunctional materials in different fields of application and to improve its chemical, physical, and mechanical properties [37]. Chitosan-gPHBV graft copolymer was synthesized and grafting of linoleic acid on chitosan were performed by condensation reaction under vacuum at $90-95^{\circ} \mathrm{C}$. Graft 


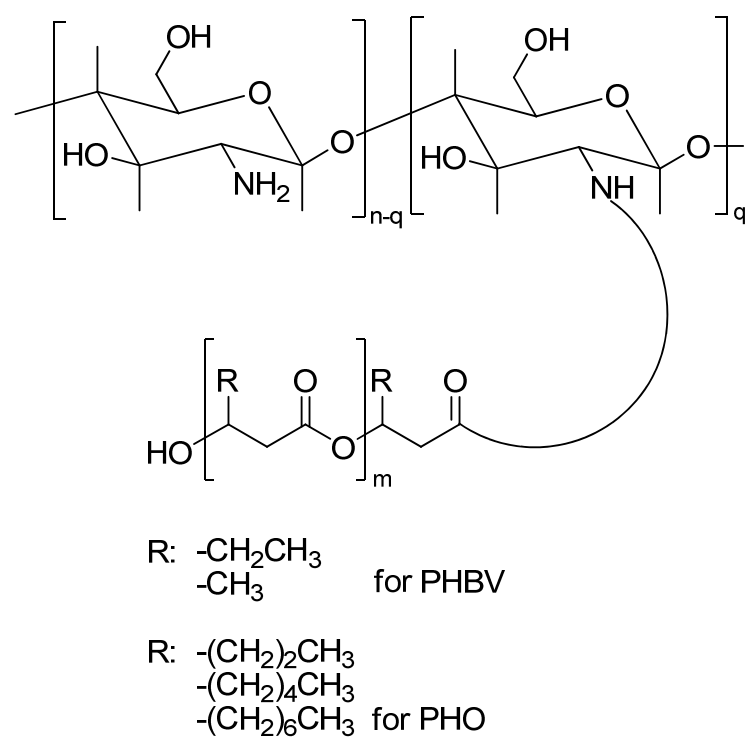

Figure 6. Chitosan-g-PHBV graft copolymer

copolymers exhibit different solubility behavior as a function of degree of substitution of $\mathrm{NH}_{2}$ in other words as a function of grafting percent such as solubility, insolubility, or swelling in $2 \mathrm{wt} \%$ acetic acid and in water while chitosan does not swell in water. Chitosan-gPHBV graft copolymer is shown in Figure 6.

\subsubsection{Sugar Grafting}

Glycopolymers are emerging as a novel class of neoglycoconjugates useful for biological studies and they are prepared either by copolymerization or grafting methods [38]. Since it has been shown that thiosugars are potent tools in glycobiology, 1-thiomaltose derivatives has been grafted onto PHAs in two ways [39]; the thiol sugar is added to the double bond and the reaction between thiol sugar and bromo end groups of polyester biosynthesized from 11-bromoundecanoic acid [40]. These new grafted polymers are insoluble in dichloromethane and chloroform, but very soluble in $N, N$-dimethylformamide and dimethyl sulfoxide, as opposed to their parent PHAs. As expected, modified PHAs are more hydrophilic than their parent compounds.

\subsubsection{PEG Grafting}

Diazo linkaged PEG, a polyazoester synthesized by the reaction of PEG and 4,4'-azobis(4-cyanopentanoyl chloride) creates PEG macro radicals which is easily attack to the double bonds of the unsaturated PHA to obtain the poly(3-hydroxyalkanoate)-g-poly(ethylene glycol) crosslinked graft copolymers [41]. Poly(3hydroxyalkanoate)s containing double bonds in the side chain (PHA-DB) were obtained by co-feeding Pseudomonas oleovorans with a mixture of nonanoic acid and anchovy (hamci) oily acid (in weight ratios of 50/50 and 70/30). PHA-DB was thermally grafted with a [41].

Graft copolymers of the saturated mclPHAs can be synthesized by using macro radicals via $\mathrm{H}$-abstraction from the tertiary carbon of the polyester [42]. Similarily, macroradicals onto the PHAs are induced by the UV irradiation via $\mathrm{H}$-abstraction in the presence of a PEG-macromonomer to prepare PEG-g-PHO graft copolymers [43]. Homogeneous solutions of poly (3hydroxyoctanoate) (PHO) and the monoacrylate-poly (ethylene glycol) (PEGMA) monomer in chloroform were irradiated with UV light to obtain PEGMA-grafted PHO (PEGMA-g-PHO) copolymers. The results of the protein adsorption and platelet adhesion tests show that the blood compatibility was also enhanced by grafting the PEGMA chains. The adsorption of proteins and

Table 2. Methods for the synthesis of the amphiphilic PHAs

\begin{tabular}{|c|c|c|c|c|c|c|}
\hline & & $\mathrm{EO}-\mathrm{C}$ & $\begin{array}{l}-\mathrm{CH}_{2} \cdot \stackrel{\mathrm{O}}{\mathrm{C}} \\
(\mathrm{PHA})\end{array}$ & & & \\
\hline \multirow{2}{*}{ Carbon Source } & \multicolumn{3}{|c|}{ Poly (3-hydroxy alkanoate) (PHA) } & \multicolumn{3}{|c|}{ Thermal and Mechanical Properties } \\
\hline & Type & Side chain $(\mathrm{R})$ & Name* & $\mathrm{T}_{\mathrm{g}}\left({ }^{\circ} \mathrm{C}\right)$ & $\mathrm{T}_{\mathrm{m}}\left({ }^{\circ} \mathrm{C}\right)$ & Elongation (\%) \\
\hline $\begin{array}{l}\text { Sugar, glucose, } \\
\text { acetic acid }\end{array}$ & $\begin{array}{l}\text { Short chain } \\
\text { length }\end{array}$ & Methyl, ethyl & $\begin{array}{l}\text { PHB } \\
\text { PHV }\end{array}$ & 15 & 170 & 5 \\
\hline $\begin{array}{l}\text { Alkanoic acids, } \\
\text { alkanes and alkanols }\end{array}$ & $\begin{array}{l}\text { Medium chain } \\
\text { length }\end{array}$ & $\begin{array}{c}\text { Propyl, butyl, } \\
\text { pentyl, hexyl, heptyl }\end{array}$ & $\begin{array}{l}\text { PHHx } \\
\text { PHHp } \\
\text { PHO } \\
\text { PHN } \\
\text { PHD }\end{array}$ & -40 & 60 & 800 \\
\hline Plant oily acids & $\begin{array}{l}\text { Long chain } \\
\text { length }\end{array}$ & $\begin{array}{l}\text { More than } 14 \\
\text { Carbon per } \\
\text { repeating unit }\end{array}$ & & -50 & 40 & Soft, sticky \\
\hline
\end{tabular}


platelets was increasingly suppressed, as the DG of PEGMA onto PHO increased. Glycerol 1, 3-diglycerol diacrylate-grafted poly(3-hydroxyoctanoate) copolymers are also prepared by heating homogeneous solutions of PHO, diacrylate monomer and benzoyl peroxide initiator [44]. The resulting copolymers have enhanced thermal properties and mechanical strengths. The surfaces and the bulk of the graft copolymers became more hydrophilic as the diglycerol-diacrylate grafting density in the copolymer increased. Many studies have reported that hydrophilic surfaces, such as those of hydro gels and PEG-grafted polymers, suppress protein adsorption and platelet adhesion. The surfaces of these graft copolymers become more hydrophilic with grafted diglycerol groups. These surface characteristics make this graft copolymer to prevent protein adsorption and platelet adhesion very effectively. As a summary, Table 2 indicates the sum of the chemical modification reactions to obtain amphiphilic PHAs. In this manner, Renard et al. achieved the amphiphilic copolymer based on PHOU and PEG [45]. Carboxilic acid terminal groups in the side chains are reacted with PEG in the presence of dicyclohexyl carbamate at room temperature. Amphiphilic graft copolymer obtained is soluble in the mixture of $\mathrm{H}_{2} \mathrm{O}$ / acetone $(80 / 20)$ whereas precursor PHOU is not soluble.

\section{Conclusions}

Microbial polyesters are biocompatible and biodegradable hydrophobic natural thermoplastics. Amphiphilic PHAs from swollen in water to soluble in water are much more desirable in the drug delivery system and tissue engineering. In most attempts to synthesize amphiphilic PHAs, degradation of the polyester chain has been unavoidable. To obtain new amphiphilic PHAs with high molecular weight and their medical applications have been attractive for scientists.

\section{Acknowledgment}

This work was financially supported by TUBITAK (grant no. 108T423) and ZKU Research Fund.

\section{REFERENCES}

[1] R. Langer and D. A. Tirrell, "Designing materials for biology and medicine," Nature, No. 428, pp. 487-492, 2004.

[2] S. Mitragotri and J. Lahann, "Physical approaches to biomaterial design," Nature Mater, No. 8, pp. 15-23, 2009.

[3] S. P. Valappil, S. K. Misra, A. R. Boccaccini, and I. Roy, "Biomedical applications of polyhydroxyalkanoates, an overview of animal testing and in vivo responses," Expert Review of Medical Devices, No. 3, pp. 853-868, 2006.

[4] A. J. Anderson and E. A. Dawes, "Occurrence, meta- bolism, metabolic role, and industrial uses of bacterial polyhydroxyalkanoates," Microbiological Reviews, No. 54, pp. 450-472, 1990.

[5] R. W. Lenz and R. H. Marchessault, "Bacterial polyesters: Biosynthesis, biodegradable plastics and biotechnology," Biomacromolecules, No. 6, pp. 1-8, 2005.

[6] B. Hazer and A. Steinbüchel, "Increased diversification of polyhydroxyalkanoates by modification reactions for industrial and medical applications," Applied Microbiology and Biotechnology, No. 74, pp. 1-12, 2007.

[7] K. Sudesh, H. Abe, and Y. Doi, "Synthesis, structure and properties of polyhydroxy alkanoates: Biological polyesters," Progress in Polymer Science, No. 25, pp. 15031555, 2000.

[8] A. Steinbüchel and B. Füchtenbusch, "Bacterial and other biological systems for polyester production," Trends in Biotechnology, No. 16, pp. 419-427, 1998.

[9] D. Y. Kim, H. W. Kim, M. G. Chung, and Y. H. Rhee, "Biosynthesis, modification, and biodegradation of bacterial medium-chain-length polyhydroxyalkanoates," Journal of Microbiology, No. 45, pp. 87-97, 2007.

[10] R. H. Marchessault, "Polyhydroxyalkanoate (PHA) history at Syracuse University and beyond cellulose," Cellulose, No. 16, pp. 357-359, 2009.

[11] W. Orts, G. Nobes, J. Kawada, S. Nguyen, G. Yu, and F. Ravenelle, "Poly (hydroxyalkanoates): Biorefinery polymers with a whole range of applications, the work of Robert H. Marchessault," Canadian Journal of Chemistry, No. 86, pp. 628-640, 2008.

[12] M. Zinn, B. Witholt, and T. Egli, "Occurrence, synthesis and medical application of bacterial polyhydroxyalkanoate," Advanced Drug Delivery Reviews, No. 53, pp. 5-21, 2001.

[13] Q. Wu, Y. Wang, and G. Q. Chen, "Medical application of microbial biopolyesters polyhydroxyalkanoates," Artificial Cells Blood Substitutes and Biotechnol, No. 37, pp. 1-12, 2009.

[14] K. Ruth, G. de Roo, T. Egli, and Q. Ren, "Identification of two acyl-CoA synthetases from Pseudomonas putida GPo1: One is located at the surface of polyhydroxyalkanoates granules," Biomacromolecules, No. 9, pp. 1652-1659, 2008.

[15] A. Steinbuchel and H. E. Valentin, "Diversity of bacterial polyhydroxyalkanoic acids," FEMS Microbiology Letters, No. 128, pp. 219-228, 1995.

[16] S. Förster and M. Antonietti, "Amphiphilic block copolymers in structure-controlled nanomaterial hybrids," Advanced Materials, No. 10, pp. 195-217, 1998.

[17] N. Hadjichristidis, M. Pitsikalis, S. Pispas, and H. Iatrou, "Polymers with complex architecture by living anionic polymerization," Chemical Reviews, No. 101, pp. 37473792, 2001.

[18] K. J. Townsend, K. Busse, J. Kressler, and C. Scholz, "Contact angle, WAXS, and SAXS analysis of poly (3-hydroxybutyrate) and poly (ethylene glycol) block copolymers obtained via azotobacter vinelandii UWD," 
Biotechnology Progress, No. 21, pp. 959-964, 2005.

[19] L. J. R. Foster, "Biosynthesis, properties and potential of natural-synthetic hybrids of polyhydroxyalkanoates and polyethylene glycols," Applied Microbiology and Biotechnology, No. 75, pp. 1241-1247, 2007.

[20] B. Hazer, "Chemical modification of synthetic and biosynthetic polyesters," in Biopolymers (Editor: A. Steinbuchel), Vol. 10, Chapter 6, pp. 181-208, WileyVCH, Weinheim, 2003.

[21] (a) S. Ilter, B. Hazer, M. Borcakl1, and O. Atıc1, "Graft copolymerisation of methyl methacrylate onto a bacterial polyester containing unsaturated side chains," Macromolecular Chemistry and Physics, No. 202, pp. 22812286, 2001. (b) B. Hazer, "Chemical modification of bacterial polyester," Current Trends in Polymer Science, No. 7, pp. 131-138, 2002. (c) B. Cakmakli, B. Hazer, and M. Borcakli, "Poly (styrene peroxide) and poly(methyl methacrylate peroxide) for grafting on unsaturated bacterial polyesters," Macromolecular Bioscience, No. 1, pp. 348-354, 2001. (d) B. Hazer, "Poly (beta-hydroxynonanoate) and polystyrene or poly (methyl methacrylate) graft copolymers: Microstructure characteristics and mechanical and thermal behavior," Macromolecular Chemistry and Physics, No. 197, pp. 431-441, 1996.

[22] F. Ravenelle and R. H. Marchessault, "One-step synthesis of amphiphilic diblock copolymers from bacterial poly ([R]-3-hydroxybutyric acid)," Biomacromolecules, No. 3, pp. 1057-1064, 2002.

[23] T. D. Hirt, P. Neuenschwander, and U. W. Suter, "Telechelic diols from poly [(R)-3-hydroxybutyric acid] and poly ([(R)-3-hydroxybutyricacid]-co-[(R)-3-hydroxyvalericacid]," Macromolecular Chemistry and Physics, No. 197, pp. 1609-1614, 1996.

[24] (a) G. R. Saad, "Calorimetric and dielectric study of the segmented biodegradable poly (ester-urethane)s based on bacterial poly [(R)-3-hydroxybutyrate]," Macromolecular Bioscience, No. 1, pp. 387-396, 2001. (b) G. R. Saad, Y. J. Lee, and H. Seliger, "Synthesis and characterization of biodegradable poly (ester-urethanes) based on bacterial poly (R-3-hydroxybutyrate)," Journal of Applied Polymer Science, No. 83, pp. 703-718, 2002.

[25] H. Erduranl1, B. Hazer, and M. Borcakl1, "Post polymerization of saturated and unsaturated poly (3-hydroxy alkanoate)s," Macromolecular Symposia, No. 269, pp. 161-169, 2008.

[26] (a) B. Hazer, O. Torul, M. Borcaklı, R. W. Lenz, R. C. Fuller, and S. D. Goodwin, "Bacterial production of polyesters from free fatty acids obtained from natural oils by Pseudomonas Oleovorans," Journal of Environmental Polymer Degradation, No. 6, pp. 109-113, 1998. (b) R. D. Ashby and T. A. Foglia, "Poly (hydroxyalkanoate) biosynthesis from triglyceride substrates," Applied Microbiology and Biotechnology, No. 49, pp. 431-437, 1998. (c) K. Fritzsche, R. W. Lenz, and R. C. Fuller, "Production of unsaturated polyesters by Pseudomonas oleovorans," International Journal of Biological Macromolecules, No. 12, pp. 85-91, 1990. (d) Y. B. Kim, R. W. Lenz, and R. C. Fuller, "Poly-3-Hydroxyalkanoates containing unsaturated repeating units produced by pseudomonas oleovorans," Journal of Polymer Science Part A: Polymer Chemistry, No. 33, pp. 1367-1374, 1995.

[27] M. Y. Lee, W. H. Park, and R. W. Lenz, "Hydrophilic bacterial polyesters modified with pendant hydroxyl groups," Polymer, No. 41, pp. 703-1709, 2000.

[28] M. Y. Lee and W. H. Park, "Preparation of bacterial copolyesters with improvedhydrophilicity by carboxylation," Macromolecular Chemistry and Physics, No. 201, pp. 2771-2774, 2000.

[29] D. J. Stigers and G. N. Tew, "Poly (3-hydroxyalkanoate)s functionalized with carboxylic acid Groups in the side chain," Biomacromolecules, No. 4, pp. 193-195, 2003.

[30] (a) M. S. Eroglu, B. Hazer, T. Ozturk, and T. Caykara, "Hydroxylation of pendant vinyl groups of poly (3-hydroxy undec-10-enoate) in high yield," Journal of Applied Polymer Science, No. 97, pp. 2132-2139, 2005. (b) E. Renard, A. Poux, L. Timbart, V. Langlois, and P. Guérin, "Preparation of a novel artificial bacterial polyester modified with pendant hydroxyl groups," Biomacromolecules, No. 6, pp. 891-896, 2005.

[31] D. M. Zhang, F. Z. Cui, Z. S. Luo, Y. B. Lin, K. Zhao, and G. Q. Chen, "Wettability improvement of bacterial polyhydroxyalkanoates via ion implantation," Surface and Coatings Technology, No. 131, pp. 350-354, 2000.

[32] M. Bear, M. Leboucher-Durand, V. Langlois, R. W. Lenz, S. Goodwin, and P. Guerin, "Bacterial poly-3-hydroxyalkenoates with epoxy groups in the side chains," Reactive and Functional Polymers, No. 34, pp. 65-77, 1997.

[33] M. Y. Lee, S. Y. Cha, and W. H. Park, "Crosslinking of microbial copolyesters with pendant epoxide groups by daimine," Polymer, No. 40, pp. 3787-3793, 1999.

[34] J. Sparks and C. Scholz, "Synthesis and Characterization of a Cationic Poly (-hydroxyalkanoate)," Biomacromolecules, No. 9, pp. 2091-2096, 2008.

[35] A. H. Arkin, B. Hazer, and M. Borcakli, "Chlorination of poly-3-hydroxy alkanoates containing unsaturated side chains," Macromolecules, No. 33, pp. 3219-3223, 2000.

[36] A. H. Arkin and B. Hazer, "Chemical modification of chlorinated microbial polyesters," Biomacromolecules, No. 3, pp. 1327-1335, 2002.

[37] (a) G. Yu, F. G. Morin, G. A. R. Nobes, and R. H. Marchessault, "Degree of acetylation of chitin and extent of grafting PHB on chitosan determined by solid state 15N NMR," Macromolecules, No. 32, pp. 518-520, 1999. (b) H. Arslan, B. Hazer, and S. C. Yoon, "Grafting of poly (3-hydroxyalkanoate) and linoleic acid onto chitosan," Journal of Applied Polymer Science, No. 103, pp. 81-89, 2007.

[38] S. Muthukrishnan, G. Jutz, X. Andre', H. Mori, and A. H. E. Müller, "Synthesis of hyperbranched glycopolymers via self-condensing atom transfer radical copolymerization of a sugar-carrying acrylate," Macromolecules, No. 38, pp. 9-18, 2005.

[39] M. Constantin, C. I. Simionescu, A. Carpov, E. Samain, and H. Driguez, "Chemical modification of poly (hydroxyalkanoates), copolymers bearing pendant sugars," 
Macromolecular Rapid Communications, No. 20, pp. 91-94, 1999.

[40] Y. B. Kim, R. W. Lenz, and R. C. Fuller, "Poly ( $\beta-$ hydroxyalkanoate) copolymers containing brominated repeating units produced by Pseudomonas oleovorans," Macromolecules, No. 25, pp. 1852-1857, 1992.

[41] B. Hazer, R. W. Lenz, B. Çakmaklı, M. Borcaklı, and H. Koçer, "Preparation of poly (ethylene glycol) grafted poly (3-hydroxyalkanoate)s," Macromolecular Chemistry and Physics, No. 200, pp. 1903-1907, 1999.

[42] (a) B. Hazer, "Poly ( $\beta$-hydroxy nonanoate) and polystyrene or poly (methyl methacrylate) graft copolymers: Microstructure characteristics and mechanical and thermal behavior," Macromolecular Chemistry and Physics, No. 197, pp. 431-441, 1996. (b) S. Ilter, B. Hazer, M. Borcakli, and O. Atici, "Graft copolymerization of methyl methacrylate onto bacterial polyester containing unsaturated side chains," Macromolecular Chemistry and Physics, No. 202, pp. 2281-2286, 2001.
[43] (a) H. W. Kim, C. W. Chung, and Y. H. Rhee, "UV-induced graft copolymerization of monoacrylatepoly(ethylene glycol) onto poly(3-hydroxyoctanoate) to reduce protein adsorption and platelet adhesion," International Journal of Biological Macromolecules, No. 35, pp. 47-53, 2005. (b) C.W. Chung, H. W. Kim, Y. B. Kim, and Y. H. Rhee, "Poly (ethylene glycol)-grafted poly (3-hydroxyundecenoate) networks for enhanced blood compatibility," International Journal of Biological Macromolecules, No. 32, pp. 17-22, 2003.

[44] H. W. Kim, M. G. Chung, Y. B. Kim, and Y. H. Rhee, "Graft copolymerization of glycerol 1,3-diglycerolate diacrylate onto poly(3-hydroxyoctanoate) to improve physical properties and biocompatibility," International Journal of Biological Macromolecules, No. 43, pp. 307 313, 2008.

[45] S. Domenek, V. Langlois, and E. Renard, "Bacterial polyesters grafted with poly (ethylene glycol): Behaviour in aqueous media," Polymer Degradation and Stability, No. 92, pp. 1384-1392, 2007. 